\title{
ACTIVIDAD CICATRIZANTE DE UNA POMADA CON ACEITE ESENCIAL DE Schinus molle L. "MOLLE” EN GANADO VACUNO CON HERIDAS INFECTADAS Y EN RATONES
}

\author{
Healing activity of ointment the essential oil of the Schinus molle L. "molle" in front to the \\ wounds infected in the cattle and in mice \\ Alba Gonzalez Alex ${ }^{1}$, Bonilla Rivera Pablo ${ }^{1}$, Arroyo Acevedo Jorge ${ }^{2}$ \\ ${ }^{1}$ Instituto de Ciencias Farmacéuticas y Recursos Naturales "Juan de Dios Guevara" Facultad de Farmacia y Bioquímica. \\ UNMSM. ${ }^{2}$ Laboratorio de Farmacología. Facultad de Medicina. UNMSM.
}

\section{RESUMEN}

En la presente investigación se evaluó la actividad cicatrizante del aceite esencial de Schinus molle L. "molle"a diferentes concentraciones, en comparación con un producto comercial. Se encontró que el aceite esencial del Schinus molle L. "molle", constituído principalmente por monoterpenos y sesquiterpenos, en pomada y teniendo como base vaselina sólida. Los resultados mostraron que el producto posee propiedades cicatrizantes frente a heridas infectadas en ganado vacuno las que sanaban de manera apropiada; así mismo, los experimentos llevados a cabo en ratones de cepa Balb C 53, corroboraron la experiencia mencionada, siendo la concentración al $2 \%$ la que presentó mayor poder cicatrizante frente a la pododermatitis y mastitis subclínicas.

Palabras clave: Schinus molle L, aceite esencial, pomada, cicatrizante, pododermatitis, mastitis.

\section{SUMMARY}

In the present investigation was evaluated the healing effect of the essential oil of Schinus molle L. "molle" to different concentrations, in comparison with a commercial product. The one was determined that the essential oil of the Schinus molle L. "molle", mostly have monoterpenoids and sesquiterpenoids in ointment having as base solid petroleum jelly. The results mostrated what the product also has healing properties front to the wounds infected in the cattle, in which they healed of appropriate way; the carried out experiments in mice cepa Balb $C_{53}$, corroborated the mentioned experience, being the concentration to $2 \%$ that presented/displayed greater to be able healing front to the pododermatitis and reported subclinical mastitis.

Key words: Schinus molle L, essential oil, oint ment, healing, pododermatitis, mastitis.

\section{INTRODUCCIÓN}

E 1 Schinus molle L. "molle" es una especie vegetal muy difundida en el Perú, siendo su desarrollo óptimo en los climas de los valles interandinos. Especie perteneciente a la familia Anacardiaceae. El uso popular medicinal ubica a las hojas del "molle" desde un repelente de mosquitos hasta un analgésico en dolores reumáticos. Se postuló que, el aceite esencial presente en las hojas del "molle" pudiera tener efectos benéficos en la cicatrización de las heridas en el ganado vacuno, cuyos resultados experimentales se verificarían mediante pruebas preclínicas en ratones albinos.

El objetivo fue evaluar la actividad cicatrizante del aceite esencial de Schinus molle L. "molle" a diferentes concentraciones, en comparación con un producto comercial frente a heridas infectadas en ganado vacuno.

\section{GENERALIDADES}

Características morfológicas. Es un árbol que crece espontáneamente en muchos lugares de América y en el Perú. La talla y grosor de este árbol varía, es de poca copiosidad, sus ramas son numerosas y quebradas, relativamente delgadas. La corteza es agrietada, hojas imparimpinadas, alternas, angostas de bordes dentados; cortamente pecioladas, coriáceas aovadas, oblongas con nervadura principal muy marcada, prominente en ambas caras. Frescas tienen un color verde claro, sabor amargo y picante. Presenta panículas de pequeñas flores verdosas, actinomorfas, pentámeras de carpelos libres o concreciones siempre unilobuladas. Los frutos son pequeñas drupas de tamaño menor al de una arveja, de color rojizo, olor aromático y sabor dulce, razón por la cual se usa en la elaboración de la chicha de molle. Las semillas que forman el fruto son pequeñas, de superficie arrugada y aspecto característico ${ }^{(1-3)}$. 
Distribución geográfica. El Schinus molle L. es propio de las regiones cálidas y secas de Sudamérica. Vive en las laderas occidentales de la región interandina, vertientes occidentales de los andes peruanos, en la costa y en los valles. Su límite superior se encuentra en el centro y sur del Perú, alrededor de 3500 msnm ${ }^{(1-3)}$.

Usos del molle. En la literatura se registran las propiedades curativas que se le asignan a las distintas partes de la planta. Hojas: Antirreumático, cicatrizante, en la limpieza de los dientes, digestivo. Fruto: Antirreumático, en la retención urinaria, emenagogo, expectorante, antiparasitario. Corteza y resina: Antirreumático, cicatrizante, en dientes careados. Otros usos: En tinción (hojas), frutos en bebidas fermentadas, como saborizante, la corteza como aromatizador. El cocimiento de hojas de molle aplicadas en baños locales desinflama la pierna de los hidrópicos y gotosos. Las hojas mojadas curan las heridas, los hombres que trabajan en las minas repelen los mosquitos colocándose una corona de hojas de molle en la cabeza ${ }^{(1-3)}$.

Los aceites esenciales. Son obtenidos del material fresco que los contienen, utilizando principalmente destilación por arrastre de vapor de agua. Obtenido el aceite esencial, éste es secado con sulfato de sodio anhidro. Son líquidos volátiles a temperatura ambiente, lo que los diferencia de los aceites fijos; densidad inferior a la del agua, índice de refracción elevado y la mayoría desvían la luz polarizada. Son lipofílicos y miscibles en los disolventes orgánicos habituales.

Son los constituyentes odoríferos o esencias de una planta. La palabra esencial fue derivada del latín "quinta essentia", que significaba el quinto elemento asignado a estos aceites, ya que la tierra, el fuego, el viento y el agua fueron considerados los cuatro primeros elementos. Los aceites esenciales son compuestos muy heterogéneos, constituidos por monoterpenos, sesquiterpenos, ácidos orgánicos, lactonas, anhídridos, éteres, fenoles y compuestos aromáticos ${ }^{(4-7)}$.

Metabolitos secundarios presentes en Schinus molle 1. "molle". El estudio fitoquímico de Schinus molle L. "molle" indica que contiene taninos, alcaloides, flavonoides, saponinas esteroidales, esteroles, terpenos y aceite esencial.

El aceite esencial presente en las hojas contiene ácido behenico, bergamota, bicyclogermacreno, borneno, cadineno, cadinol, calacoreno, calamenediol, calamaneno, canfeno, carvacrol, ácido gálico, butirato de geraniol, limoneno, mirceno, ácido linoleico, ácido palmítico, entre otros ${ }^{(47)}$.

Propiedades farmacológicas de los aceites esenciales. Poder antiséptico, propiedades antiespasmódicas y sedantes, estimulan la secreción gástrica por lo que son digestivos y estomáquicos ${ }^{(4)}$; estimulación uterina, antiinflamatorio en casos de cervicitis y vaginitis. El aceite esencial de Schinus molle $L$. no presenta toxicidad en animales ni en los seres humanos ${ }^{(3,8)}$. Según investigación realizada por Guba R, en 2008, los aceites esenciales no demostraron ser tóxico-carcinógenos en los animales de experimentación utilizados ${ }^{(8)}$.

Actividad antibacteriana in vitro del aceite esencial de Schinus molle L. Estudios reportados concluyeron que, el aceite esencial de Schinus molle $L$. muestra actividad antibacteriana contra cepas Gram (+), como Staphylococcus aureus, y contra Gram (-) tales como: Escherichia coli, Enterobacter, Shigella flexneri, Klebsiella pneumoniae y Proteus vulgaris. Asimismo, Pauli A. ${ }^{(9)}$ evaluó las propiedades antimicrobianas de los aceites esenciales, llegando a la conclusión que éstos tienen acción inhibitoria frente a bacterias, hongos y levaduras.

\section{Anatomía animal.}

Piel. El grosor de la piel del vacuno es mayor que el de cualquier otro animal doméstico; en general tiene de 3 a $4 \mathrm{~mm}$, pero en la base de la cola y en el corvejón tiene cerca de $5 \mathrm{~mm}$ y, en la papada 6 y $7 \mathrm{~mm}$.

Pezuñas. Cuatro en cada miembro, cubren los extremos de los dedos.

Ubre. Las mamas son llamadas popularmente ubre y en general son cuatro. Son glándulas cutáneas modificadas, que están asociadas funcionalmente con los órganos genitales, de forma que pueden ser consideradas como accesorias de ellos. Cada glándula tiene la forma de un cono corto, aplanado, comprimido transversalmente y tiene una superficie media plana. Las glándulas mamarias están formadas por la masa glandular o cuerpo de la glándula y la papila o tetina. La base está relacionada con la pared abdominal, a las que se une por medio de un tejido areolar, que contiene un plexo venoso, los nódulos linfáticos mamarios y una cantidad variable de grasa. El vértice está constituido por la tetina, que también está aplanada transversalmente y cuya longitud varía de 2,5 a $5 \mathrm{~cm}$. Entre la base de las tetinas se encuentra el surco ínter-mamario. Sobre el vértice de cada una de las tetinas, normalmente existen dos pequeños orificios situados juntos, éstos son las aberturas de los conductos lactíferos ${ }^{(10)}$.

Heridas en el ganado vacuno. La reparación de los tejidos comprende dos procesos distintos: (1) La regeneración o sustitución de las células lesionadas por otras de la misma clase, a veces sin que queden huellas residuales de la lesión anterior, y (2) La sustitución por tejido conjuntivo llamado fibroplasia o fibrosis, que 
deja una cicatriz permanente.

En la mayoría de los casos, estos dos procesos contribuyen a la reparación ${ }^{(9,10)}$.

\section{Infecciones tisulares comunes causadas por heridas infectadas en ganado vacuno.}

Pododermatitis infecciosa. Es una enfermedad del ganado vacuno caracterizada por inflamación de los tejidos sensibles de las pezuñas y produce cojera intensa. Esta enfermedad es atribuida a la bacteria Fusobacterium necrophorum. Se reporta la sinergia de este germen con Dichelobacter nodosus y B. melaninogenicus. La enfermedad ocurre durante todas las estaciones, pero es más frecuente en época lluviosa; sin embargo, se sabe que ha ocurrido durante el tiempo seco, cuando el suelo esta firme y el ganado tiene acceso a hoyos de agua estancada. Probablemente el suelo duro y seco predispone al tejido interdigital y a los talones a sufrir contusiones. Una vez que ocurre una lesión cutánea los organismos presentes en aguas estancadas infectan fácilmente la herida ${ }^{(11,13)}$.

Mastitis. En la vaca lechera, la mastitis puede definirse como inflamación de la glándula mamaria casi siempre causada por infección por patógenos bacterianos o micóticos. Los organismos contaminantes incluyen a Streptococcus agalactiae, Streptococcus dysgalactiae, Staphylococcus aureus y Mycoplasma sp. Los factores que predisponen a la infección dentro de la glándula son: poca higiene durante el ordeño, máquinas de ordeño defectuosas, manejo erróneo del ordeño, lesiones en las tetillas, úlceras en las tetillas y poblaciones de patógenos en el medio ambiente ${ }^{(12)}$.

\section{MATERIALES Y EQUIPOS}

\section{Material biológico}

Ratones albinos consanguíneos, Cepa Balb C 53 procedentes del Instituto Nacional de Salud de ambos sexos, de un mes de edad, de 20 a $25 \mathrm{~g}$ de peso corporal promedio. Ganado vacuno.

\section{Material farmacológico}

Medicamento tópico o producto comercial (pomada con actividad cicatrizante).

\section{Material básico de vidrio}

\section{Equipos}

Destilador por arrastre de vapor. Espectrómetro UV/Visible con arreglo de diodo HEWLETT PACKARD.

\section{MÉTODOS}

\section{Colección de la muestra vegetal}

Se colectaron $20 \mathrm{Kg}$ de hojas de Schinus molle L. en el departamento de Ayacucho, a 3000 msnm.

\section{Procedimiento de obtención del aceite esencial}

El aceite esencial de Schinus molle L. fue obtenido en el Laboratorio de Docencia, Investigación y Producción de Farmacia y Bioquímica, de la Universidad San Cristóbal de Huamanga - Ayacucho, por el método de arrastre de vapor. Las pruebas de autenticidad se realizaron en el Centro de Desarrollo, Análisis y Control de Calidad de Medicamentosy Fitomedicamentos (EFPFYB) - Taller de Mecánica HOLGER K. HANSEN (FIQ), en la Universidad de Huamanga.

\section{Ensayo de miscibilidad del aceite esencial}

Se evaluó cualitativamente la miscibilidad del aceite esencial en solventes de polaridad creciente (Tabla 1).

\section{Métodos físico-químicos yensayos organolépticos}

Índice de refracción: Real Farmacopea Española, 2da. Edición. Pag. 23.

Densidad: Real Farmacopea Española, 2da. Edición. Pag. 23. Espectro UV: CEDACMEF - oo6 - Aoo6 - 2006.

\section{Elaboración de pomada}

Se derritieron $100 \mathrm{~g}$ de vaselina sólida por vez, añadiendo directamente al medio el aceite esencial correspondiente a las distintas concentraciones motivo de experimento $(1,75 \%, 2 \%$ y $3,75 \%)$, siguiendo parámetros de elaboración ${ }^{(14)}$.

\section{Procedimiento en pododermatitis}

1. Se identifica a los animales que presentan signos de pododermatitis.

2. Tener el equipo limpio y desinfectado.

3. Conducir al animal hasta el sitio de sujeción.

4. Sujetar al animal y usar la jaula de recorte de pezuña.

5. Limpiar la base del casco con el cuchillo de limpieza y agua limpia, hasta descubrir la herida a tratar.

6. Aplicar la pomada en el área afectada ${ }^{(15)}$.

\section{Estandarización del método}

Se utilizaron dos vacas lecheras, con característica 
de edades y razas semejantes, a las que se les hizo un corte a nivel de la panza de dos centímetros de longitud, para favorecer la contaminación de la herida por agentes microbianos (durante el reposo), siendo esto corroborado por el médico veterinario encargado.

Una vez que la infección fue certificada se procedió a untar pomada de "molle" a la concentración de $3,5 \%$ sobre las heridas, cada ocho horas por espacio de siete días, al cabo de los cuales se evaluó la cicatrización de las mismas.

\section{Prueba de la actividad cicatrizante de la po- mada de "molle"}

Las concentraciones utilizadas en la pomada fueron de $3,5 \%, 2 \%$ y $1,75 \%$, dispuestas de la siguiente manera:

- Cinco vacas tratadas con pomada al 3,5\% de aceite esencial de "molle".

- Cinco vacas tratadas con pomada al $2 \%$ de aceite esencial de "molle".

- Tres vacas tratadas con pomada al 1,75\% de aceite esencial de "molle".

- Tres vacas como grupo control.

- Tres vacas comogrupoque recibió el producto comercial.

\section{Actividad cicatrizante de la pomada de "molle" sobre} lesiones inducidas en ratones albinos Balb C 53.

Se utilizaron 40 ratones albinos, distribuidos al azar en 5 grupos; a los que se depiló el lomo con un depilatorio comercial, después de un reposo de 24 horas, se realizaron dos incisiones sobre el lomo. Se aplicó tópicamente dos veces al día por siete días: un grupo recibió sólo la base de la pomada (vaselina 100\%, constituyéndose en el grupo control); tres grupos recibieron la pomada en tres niveles de concentración $(1,75$; 2.0 y $3,75 \%$ respectivamente) y un grupo el producto comercial, siendo el grupo de referencia farmacológico. Luego se les sacrificó por dislocación cervical y, en una lesión, se procedió a medir la fuerza o tensión en gramos que abriera la herida cicatrizada utilizando un dinamómetro; la otra incisión fue retirada y conservada en formol al 10\% para analisis histopatológico ${ }^{(16)}$.

\section{ANÁLISIS ESTADÍSTICO}

Los datos se expresan en valores medios \pm error estándar, para establecer la diferencia significativa se utiliza una $\mathrm{p}<0,05$ haciendo uso del análisis de varianza $\mathrm{y}$, para establecer si los diferentes tratamientos son significativos, se aplica el test de múltiples comparaciones. Se utiliza el programa estadístico SPSS versión 13.16.

\section{RESULTADOS}

Tabla 1. Ensayo de miscibilidad del aceite esencial de Schinus molle L.

\begin{tabular}{ccccccc}
\hline Solvente & Éter de petróleo & n-hexano & Cloroformo & Acetato de etilo & Metanol & Etanol \\
\hline Aceite esencial & +++ & +++ & ++++ & ++++ & +++ & +++ \\
\hline
\end{tabular}

Tabla 2. Características físico-químicas y organolépticas del aceite esencial de Schinus molle L.

\begin{tabular}{cc}
\hline Indice de refracción & 1,4780 \\
Densidad & $0,8658 \mathrm{~g} / \mathrm{mL}$ \\
Espectros UV & $\lambda 210 \mathrm{~nm}: 1,959 ; \lambda 225 \mathrm{~nm}: 1,838 ; \lambda 265 \mathrm{nm:0,665}$ \\
Olor & picante \\
Sabor & amargo \\
Color & ámbar \\
Aspecto & viscoso \\
\hline
\end{tabular}

Tabla 3. Prueba piloto de la actividad cicatrizante de la pomada del aceite esencial de Schinus molle L. al $3.75 \%$ en vacas con Pododermatitis.

\begin{tabular}{ccc}
\hline Vacas tratadas & Vaca № $\mathbf{1}$ & Vaca № 2 \\
\hline Pomada al 3,75\% & ++++ & +++ \\
Blanco & ------- & ----- \\
\hline
\end{tabular}


Tabla 4. Prueba de la actividad cicatrizante de la pomada del aceite esencial de Schinus molle L. en ganado vacuno a diferentes concentraciones vs Producto comercial (Aftisanol)

\begin{tabular}{|c|c|c|c|}
\hline Vacas tratadas & Diagnóstico clínico & Concentración al 3,75 \% & Producto comercial \\
\hline $\mathrm{N}^{\mathrm{o}} 147$ & pododermatitis & ++++ & ++++ \\
\hline $\mathrm{N}^{\mathrm{o}} 121$ & pododermatitis & ++++ & ++++ \\
\hline $\mathrm{N}^{\mathbf{o}} 89$ & $\begin{array}{l}\text { Mastitis con herida } \\
\text { supurante externa }\end{array}$ & ++++ & ++++ \\
\hline CUTA & Pododermatitis & ++ & ++++ \\
\hline \multirow[t]{2}{*}{$\mathrm{N}^{\mathrm{o}} 124$} & Herida en el lomo & ++++ & ++++ \\
\hline & & Concentración al $2 \%$ & \\
\hline $\mathrm{N}^{\mathrm{o}} 187$ & Herida superficial & ++++ & ++++ \\
\hline $\mathrm{N}^{\mathrm{o}} 115$ & Pododermatitis & ++++ & ++++ \\
\hline $\mathrm{N}^{\mathrm{o}} 207$ & Pododermatitis & ++++ & ++++ \\
\hline $\mathrm{N}^{\mathrm{o}} 190$ & $\begin{array}{l}\text { Mastitis con herida } \\
\text { supurante externa }\end{array}$ & ++++ & ++++ \\
\hline \multirow[t]{2}{*}{$\mathrm{N}^{\circ} 47$} & Herida en el lomo & +++ & ++++ \\
\hline & & Concentración al 1,75\% & \\
\hline $\mathrm{N}^{\mathbf{o}} 89$ & $\begin{array}{l}\text { Mastitis con herida } \\
\text { supurante externa }\end{array}$ & + & ++++ \\
\hline $\mathrm{N}^{\mathrm{o}} 47$ & Herida en el lomo & ++ & ++++ \\
\hline $\mathrm{N}^{\circ} 187$ & Herida superficial & +++ & ++++ \\
\hline
\end{tabular}

Tabla 5. Valores medios de la fuerza de tensión para abrir las lesiones en proceso de cicatrización del lomo de ratones.

\begin{tabular}{|c|c|c|c|c|c|c|}
\hline \multirow{2}{*}{ Tratamiento } & \multirow{2}{*}{$\begin{array}{c}\text { Media } \\
\text { (g) }\end{array}$} & \multirow{2}{*}{$\begin{array}{c}\text { Error } \\
\text { estándar }\end{array}$} & \multicolumn{2}{|c|}{ Intervalo de Confianza $95 \%$} & \multirow{2}{*}{ Mínimo } & \multirow{2}{*}{ Máximc } \\
\hline & & & Superior & Inferior & & \\
\hline Vaselina $100 \%$ & 2,88 & 0,23 & 2,34 & 3,41 & 2 & 4 \\
\hline Aftisanol tintura & 10,25 & 0,59 & 8,85 & 11,65 & 8 & 13 \\
\hline Pomada $3,75 \%$ & 6,00 & 0,38 & 5,11 & 6,89 & 5 & 8 \\
\hline Pomada $2,0 \%$ & 7,50 & 0,46 & 6,41 & 8,59 & 5 & 9 \\
\hline Pomada $1,75 \%$ & 4,13 & 0,35 & 3,30 & 4,95 & 3 & 6 \\
\hline
\end{tabular}

Tabla 6. Análisis de varianza de los datos de la fuerza de tensión para abrir las lesiones en proceso de cicatrización del lomo de los ratones.

\begin{tabular}{cccccc}
\hline & Sum of Squares & df & Mean Square & F & Significancia \\
\hline Between Groups & 267,85 & 4,00 & 66,96 & 47,59 & 0,000 \\
Within Groups & 49,25 & 35,00 & 1,41 & \\
Total & 317,10 & 39,00 & & \\
\hline
\end{tabular}


Tabla 7. Test post hoc de múltiples comparaciones de los datos de la fuerza de tensión para abrir las lesiones en proceso de cicatrización del lomo de ratones.

\begin{tabular}{|c|c|c|c|c|c|c|}
\hline \multirow{2}{*}{ (I) Tratamiento } & \multirow{2}{*}{ (J) Tratamiento } & \multirow{2}{*}{$\begin{array}{l}\text { Diferencias } \\
\text { de medias }\end{array}$} & \multirow{2}{*}{$\begin{array}{l}\text { Error } \\
\text { estándar }\end{array}$} & \multirow{2}{*}{ Significancia } & \multicolumn{2}{|c|}{ Intervalo de confianza $95 \%$} \\
\hline & & & & & Inferior & Superior \\
\hline \multirow[t]{4}{*}{ Vaselina $100 \%$} & Aftisanol tintura & $-7,38$ & 0,59 & 0,000 & $-8,58$ & $-6,17$ \\
\hline & Pomada $1.75 \%$ & $-3,13$ & 0,59 & 0,000 & $-4,33$ & $-1,92$ \\
\hline & Pomada $2.0 \%$ & $-4,63$ & 0,59 & 0,000 & $-5,83$ & $-3,42$ \\
\hline & Pomada $3.75 \%$ & $-1,25$ & 0,59 & 0,042 & $-2,45$ & $-0,05$ \\
\hline \multirow[t]{4}{*}{ Aftisanol tintura } & Vaselina $100 \%$ & 7,38 & 0,59 & 0,000 & 6,17 & 8,58 \\
\hline & Pomada $1.75 \%$ & 4,25 & 0,59 & 0,000 & 3,05 & 5,45 \\
\hline & Pomada $2.0 \%$ & 2,75 & 0,59 & 0,000 & 1,55 & 3,95 \\
\hline & Pomada $3.75 \%$ & 6,13 & 0,59 & 0,000 & 4,92 & 7,33 \\
\hline \multirow[t]{4}{*}{ Pomada $1,75 \%$} & Vaselina $100 \%$ & 3,13 & 0,59 & 0,000 & 1,92 & 4,33 \\
\hline & Aftisanol tintura & $-4,25$ & 0,59 & 0,000 & $-5,45$ & $-3,05$ \\
\hline & Pomada $2.0 \%$ & $-1,50$ & 0,59 & 0,016 & $-2,70$ & $-0,30$ \\
\hline & Pomada $3.75 \%$ & 1,88 & 0,59 & 0,003 & 0,67 & 3,08 \\
\hline \multirow[t]{4}{*}{ Pomada $2,0 \%$} & Vaselina $100 \%$ & 4,63 & 0,59 & 0,000 & 3,42 & 5,83 \\
\hline & Aftisanol tintura & $-2,75$ & 0,59 & 0,000 & $-3,95$ & $-1,55$ \\
\hline & Pomada $1.75 \%$ & 1,50 & 0,59 & 0,016 & 0,30 & 2,70 \\
\hline & Pomada $3.75 \%$ & 3,38 & 0,59 & 0,000 & 2,17 & 4,58 \\
\hline \multirow[t]{4}{*}{ Pomada 3,75\% } & Vaselina $100 \%$ & 1,25 & 0,59 & 0,042 & 0,05 & 2,45 \\
\hline & Aftisanol tintura & $-6,13$ & 0,59 & 0,000 & $-7,33$ & $-4,92$ \\
\hline & Pomada $1.75 \%$ & $-1,88$ & 0,59 & 0,003 & $-3,08$ & $-0,67$ \\
\hline & Pomada $2,0 \%$ & $-3,38$ & 0,59 & 0,000 & $-4,58$ & $-2,17$ \\
\hline
\end{tabular}

Se observa que existe diferencia significativa a una $p<0,05$ al comparar los diferentes tratamientos entre sí.

\section{DISCUSIÓN}

Investigaciones realizadas por Nagaraja TG et al. en 1998 en Actinomyces pyogenes determinaron inhibición de crecimiento bacteriano con presencia de proteasas y neurominidasas en bacterias frente a aceites esenciales, siendo ambas bacterias Gram positivas (17). El mecanismo de acción de la actividad del aceite esencial no ha sido dilucidado, pero si consideramos su valor antiséptico podemos relacionarlos con los mecanismos de acción de los antisépticos utilizados comúnmente, éstos mayormente favorecen la precipitación de proteínas en las bacterias, mientras que los antibióticos presentan desde inhibición de la síntesis de la pared celular hasta errores de trascripción de proteínas, con la consiguiente lisis celular ${ }^{(18)}$.

En 1998, Carrasco E. ${ }^{(3)}$ determinó que el aceite esencial de Schinus molle L., obtenido del fruto, presentaba actividad antimicrobiana contra cepas de Staphylococcus aureus entre otros y siendo este microorganismo un Gram positivo, a semejanza del Fusobacterium necrophorum causante de pododermatitis en el ganado vacuno; es que el aceite esencial de "molle" podría actuar inhibiendo la síntesis de su pared celular o favoreciendo la precipitación de proteínas.

Al realizar una prueba piloto de la actividad cicatrizante de la pomada del aceite esencial de Schinus molle $L$. al 3,75\% en vacas con Pododermatitis, se observó que favorece la cicatrización de las heridas infectadas (Tabla 3 ).

También se observó que las concentraciones de $3,75 \%$ y $2 \%$ favorecen una evolución clínica (cicatrización) en mayor grado que la de $1,75 \%$ (Tabla 4).

En las pruebas in vitro realizadas en el laboratorio de Farmacología de la Facultad de Medicina de la UNMSM, con ratones albinos consaguíneos, cepa Balb 


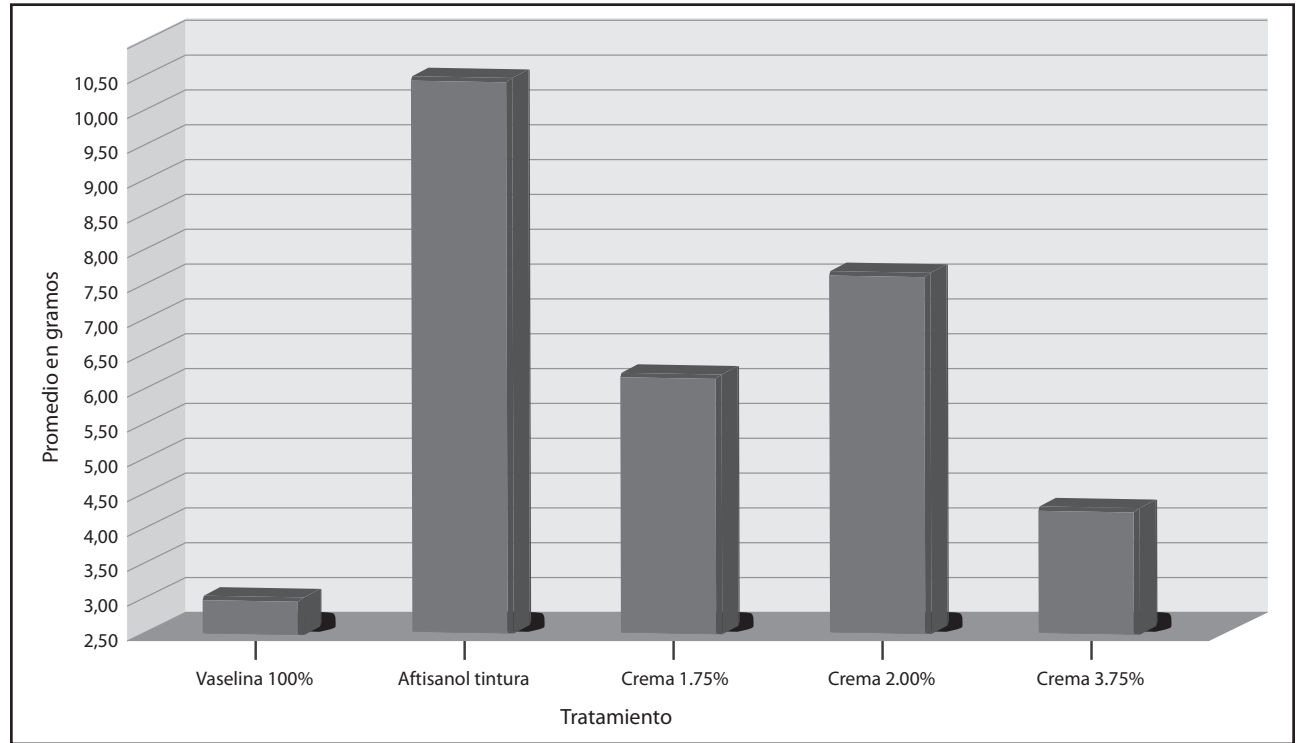

Figura 1. Actividad cicatrizante expresado como fuerza de tensión para abrir lesiones en proceso de cicatrización en el lomo de ratones.

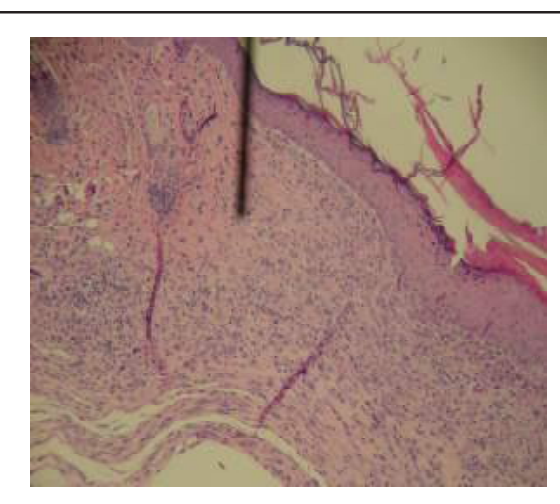

Figura 2. Control de lesión sin tratamiento sobre el lomo del ratón de experimentación.

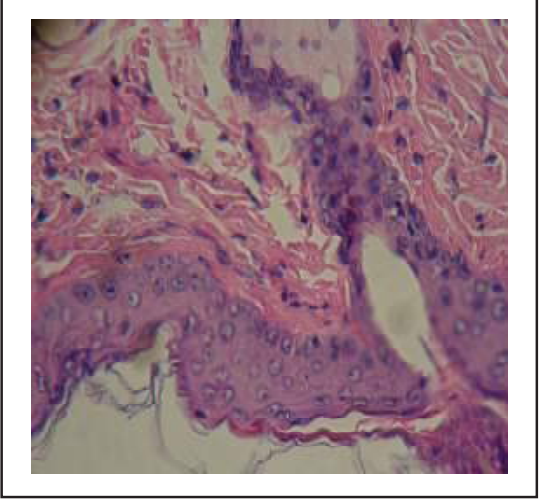

Figura 3. Cicatrizado, presencia de grueso tejido sin llegar a ser normal. Lomo del ratón de experimentación.

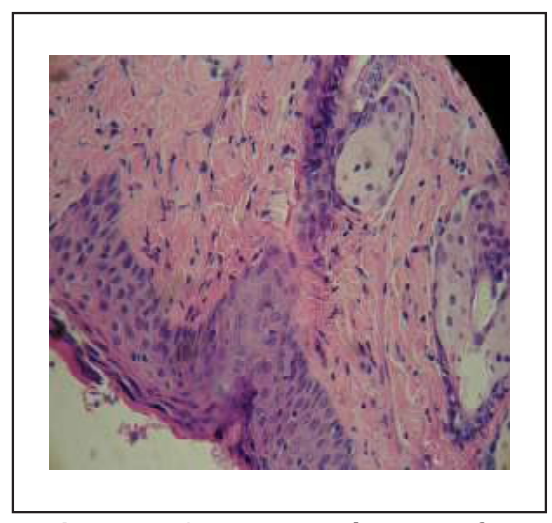

Figura 4. Cicatriz completa, con formación de capa corneal, superficie del lomo del ratón de experimentación.

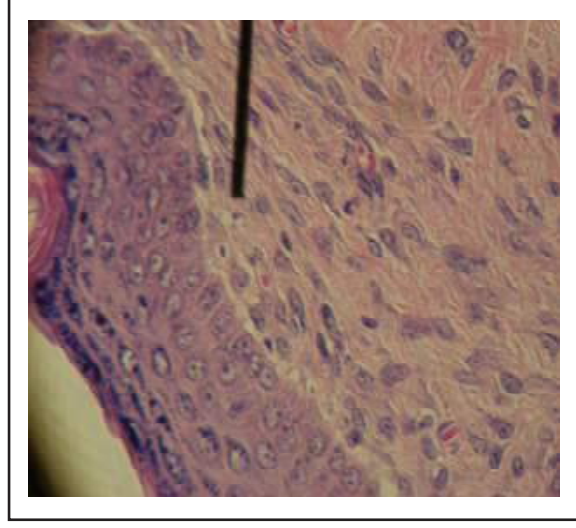

Figura 5. Hay cicatrización, engrosamiento del epitelio por presencia de queratina superficial, sobre el lomo del ratón.

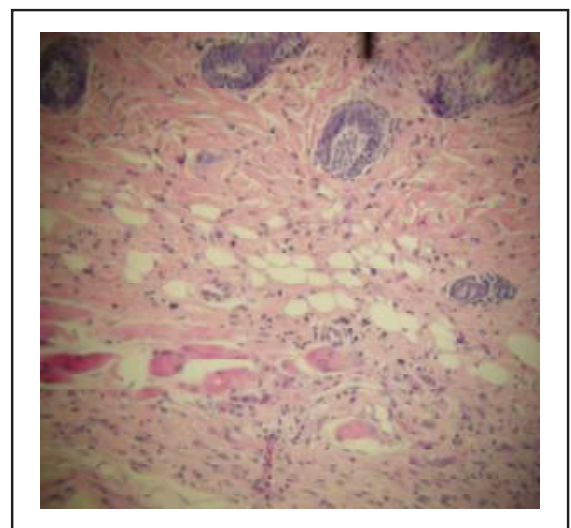

Figura 6. Existe cicatrización, paredes con los tejidos cicatrizales, zona ausente de folículo piloso en herida superficial en el lomo del ratón. 
C 53 procedentes del Instituto Nacional de Salud MINSA, se observaron los resultados de la actividad cicatrizante de la pomada del aceite esencial de Schinus molle $L$. (Figura 1), y en el estudio histopatológico de los animales que recibieron tópicamente pomada al 2,0\% se observaron paredes con tejidos en cicatrización, seguidas por los que usaron la crema en 3,75\% y 1,75\% (Figuras 2-6).

Puede observarse, en la Tabla 5, que el error estándar presente en los grupos de experimentación es muy cercano, siendo mayor el del producto de marca, y entre las concentraciones probadas, la de $2 \%$. Cuando analizamos en función del coeficiente de variación, los datos recogidos para la concentración al 2\% y la del producto comercial, observamos que los valores son prácticamente los mismos, por lo cual afirmamos que los grupos utilizados en esta prueba tuvieron igual variabilidad.

$$
\begin{aligned}
& C . V_{2 \%}=0,46 / 7,5(100)=6,0 \\
& C . V_{\text {AFTISANOL }}=0,59 / 10,25(100)=5,7
\end{aligned}
$$

En las Tablas 6 y 7, se observa que al aplicar los diferentes tratamientos existen diferencias significativas $(\mathrm{p}<0,05)$ al comparar los diferentes tratamientos.

Control de lesión sin tratamiento: se aprecia continuidad y cicatrización incompleta, reacción inflamatoria, fibroblastos abundantes sobre el lomo del ratón de experimentación (Figura 4). Existe cicatrización, paredes con los tejidos en cicatrización, zona ausente de folículo piloso en herida superficial en el lomo del ratón (Figura 8). Es decir los cortes histológicos confirman la óptima cicatrización en las heridas tratadas con la pomada a concentración de $2 \%$ de aceite esencial de Schinus molle L.

Se puede concluir que, la pomada a concentración de $2 \%$ de aceite esencial de Schinus molle $L$. contribuye en la cicatrización de las heridas expuestas en el ganado vacuno y en ratones albinos Balb C 53, y que los valores medios de la fuerza de tensión a un intervalo de confianza al $95 \%$ denota que la pomada al $2 \%$ presenta una cicatrización con mayor resistencia a rotura frente a las concentraciones al 1,75\% y $3,75 \%$.

\section{REFERENCIAS BIBLIOGRAFICAS}

1. Madrid GP. El fruto de Schinus molle L. su interés bromatológico en la elaboración de la llamada chicha de molle. Trabajo de Aptitud Profesional para optar el Título de Químico Farmacéutico. UNMSM. Lima 1992.

2. Oré GR. Estudio químico de las hojas de Schinus mo- lle L. Tesis para optar al Título Profesional de Químico Farmacéutico. UNMSM. Lima 1997.

3. Carrasco RE. Estudio de los aceites y determinación de la actividad antimicrobiana del fruto de Schinus molle $L$. Tesis de Maestría en Recursos Vegetales y Terapéuticos. UNMSM. Lima 1998.

4. Bruneton J. Farmacognosia. Fitoquímica. Plantas medicinales. 2da. Edición. Editorial Acribia. Zaragoza 2001.

5. Lock O. Investigación Fitoquímica. Primera Edición. Fondo Editorial de la Pontificia Universidad Católica. Lima 1988.

6. Lock O. Investigación fitoquímica. Segunda Edición. Fondo Editorial de la Pontificia Universidad Católica. Lima 1994.

7. Kuklinski C. Farmacognosia. Estudio de las drogas y sustancias medicamentosas de origen natural. Editorial Omega S.A. Barcelona 2000.

8. Guba R. Toxicity Myths-essential oils and their carcinogenic potencial. Center for Aromatic Medicine. Australia 2008.

9. Pauli A. Antimicrobial properties of essential oil constituents. International journal of aromotherapy 2001; $11(3): 126-33$.

10. Sisson y Grossman. Anatomía de los animales domésticos. 5ta. Edición. Tomo I. Salvat editores S.A. Barcelona 1982.

11. Colección "Biblioteca del campo". Manual Agropecuaria. Editorial Lexus. Bogotá 2002.

12. Robbin S. Patología estructural y funcional. 6ta edición. Editorial McGraw - Hill. Interamericana. Madrid 1999.

13. Merck y Co. INC. El manual merck de veterinaria. Ed Centrum zera. Edición. Madrid 1988.

14. Trillo F. Farmacia Galénica. ıra. Edición. Ed. Limusa S.A. Madrid 1993.

15. Battaglia RA, Mayrose VB. Manual de ganado y aves de corral. Ed. Limusa S.A. Bogotá 1987.

16. Arroyo J, Rojas J, Chenguyén J. Manual de Modelos Experimentales de Farmacología, Lima 2004.

17. Nagaraja TG et al. Biochemical and biological characterization and ribotyping of Actinomyces pyogenes and Actinomyces pyogenes like organism from liver abscesses in cattle. Elsevier Veterinary Microbiology 1998 April; $61(4): 289-303$.

18. Velásquez. Farmacología. 16a. Edición. Ed. Interamericana - McGraw - Hill. México DF 1996.

Manuscrito recibido el: 30/11/2009

Aceptado para su publicación el: 07/01/2010

\section{Correspondencia:}

Dr. Pablo Enrique Bonilla Rivera

Dirección: Jr. José María Plaza № 274 Lima 11 - Perú.

E-mail: pbonillar@unmsm.edu.pe 